\title{
FORUM
}

\section{The use of radar: a practical suggestion}

\author{
from Commandant L. Oudet
}

VERY shortly after the second world war merchant seamen found that they had inherited a device which shipbuilders and owners fondly imagined would prove to be an infallible safeguard against navigational hazards: this was radar. After fifteen years had been devoted to examining the disappointing results provided by the new panacea, the International Conference on Safety of Life at Sea, held in London in 1960 , finally published a radar code. So eagerly had this code been awaited that the Conference recommended its issue without waiting for the new international convention to be implemented.

The radar code has practically concluded the long series of publications that paved the way to its formulation, and there can be no doubt that it has given seamen what they were waiting for. In the course, however, of the search for correct radar procedure, a discussion was started, under the auspices of the Institute of Navigation, on the subject of the Regulations themselves. The debate opened with a mathematical study of collisions ${ }^{1}$ published by $\mathrm{Mr}$. D. H. Sadler in 1957 , and ended with the report ${ }^{2}$ of the meeting held at the Institute in April 1 963, with which were included a number of papers read at the meeting.

Among these, Captain Wepster's was outstanding for its realistic approach, treating the problem on the same lines as, a year earlier, he had followed in his study of bridge layout ${ }^{3}$. In his view, deficiencies in radar installations are largely responsible for the frequency of collisions, and to remedy this he suggests in the first place that a permanent working party should study the lessons to be drawn from accidents, and produce constructive criticism of the equipment supplied by manufacturers. As a start, he gives a table of the standards of performance demanded by his own Company, with the corresponding fall noted in the accident rate.

The discussions on the Regulations opened up other profitable lines of enquiry, but Captain Wepster's contribution is particularly worth studying, since it provides a sound scientific approach to the problem of collisions by applying the experimental method. Equipment that has been tested and proved in one Company's ships will obviously serve equally well in others.

My present purpose, then, is to take my cue from Captain Wepster and draw attention to a number of faults in shipborne radar. Articles of mine on this subject ('Les auxiliaires du radar, un travail soigne', Journal de la Marine Marchande, 2 I August $195^{8}$ and 7 January 1960), already published in France, have failed so far to influence manufacturers, but if I persevere I may still ram the point home.

As far as the radar screen is concerned, manufacturers still offer a choice of 'ship's head-upwards' or 'north-upwards'. The latter gives a gyro-stabilized picture, the advantages of which are obvious. Navigators, however, are so accustomed to having the ship's head always in the same place that they instinctively prefer the other form of presentation. 
The only rational solution is to reconcile both views by keeping the ship's head-upwards picture and at the same time stabilizing the screen itself and the reflection-plotter. This system, still used only infrequently, has, indeed, several disadvantages. It produces some confusion on the screen during manouvre, so that navigators often seem to prefer the fixed screen with ship's head-upwards, as found on most radar sets in merchant ships-a system on whose shortcomings there is no need to enlarge: when a ship is being manœuvred with a view to avoiding collision, it produces a circular displacement of the echo that gives a false impression of the effectiveness of the manœuvre.

I am myself firmly in favour of the compass-stabilized screen, whose faults could be mitigated and even eliminated at the cost of a certain amount of technical research. No effort should be spared to find the only logical solution. The navigator would then see the screen just as he sees the compass-card or the sea-scape around him. For centuries the magnetic needle has had a rose superimposed upon it, for just this purpose of harmonizing the compass and the seapicture. When the ship turns to starboard the sea seems to turn with it. This, and not what is called 'true-motion', is what has to be achieved on the radar screen. In the first place, that motion is not in fact 'true', for it makes no allowance for current or drift, and secondly many systems call for the ship's speed to be fed in manually and not recorded by log, so that in alterations of speed inertia is left out of account. It is a difficult and fruitless task to introduce speed into the radar set. Rather than do so automatically into an apparatus that for this reason shelves a fundamental difficulty, it would be better to give the navigator an accurate speed-indicator, an instantaneous log from which at any moment he could read his true speed. From this he could judge his stoppingdistance, provided, of course, that this had been correctly measured, for the usual conditions of loading and for speeds used in practice during thick weather:

Another desirable device for the proper use of radar is a clock [similar to the wartime zig-zag clock] fitted with alarm-bells-each of these paired with an illuminated indicator-to remind the officer on watch to note, at regular intervals of time, bearings and distances in relation to other ships. Broadly speaking, time and speed are the two factors that determine manœuvre. At every moment; then, these must be immediately visible to the officer on watch. When you see how magnificently the time is displayed at an airport or how instantly speed can be seen on the dashboard of an automobile, there is something quite pathetic in the sight of a modern ship's bridge, with the time indicated by a marine chronometer: an excellent instrument, but one whose design has remained unchanged since the days of sail.

The whistle, another essential safety precaution in fog, can be fitted with an automatic mechanism. So far this has been governed by a simple motor that controls the timing of the blasts. In future, the officer on watch should be able to regulate the observation whistle sequence through the whole necessary range of timing. In this connection, the view of the 1960 Conference should be noted: 'In all circumstances it should be possible for the radar to be operated by the officer of the watch'. This does not mean, of course, that in all cases he should be alone on the bridge, but that, when he is alone, he must be able to do everything that needs doing; in particular he must be able to see, to hear, and to detect the presence of other ships. In the open sea, with no ships in his vicinity; this presents no difficulty. Since, however, detection momentarily interferes with the visual watch, while the whistle interrupts the listening watch, it is 
important to make whistle-blasts coincide with radar-observation. To put it more exactly, one might say that the alarm-bell and the illuminated indicator should come into operation, whatever the timing of the whistle-blasts, ten seconds before each of the latter, and that the officer on watch should observe the screen immediately they sound.

So long as there is no echo to be seen, he has nothing to plot and his visual watch is interrupted only very briefly. To plot a single echo should not extend this interruption at all considerably. The bridge should carry the equipment needed to make it as simple as possible to record the data relating to any echoes that are detected. Captain Wepster wryly remarks that the lack of any written record of observations is regrettable, but so long as no collision occurs it does not matter very much. At the same time it must not be forgotten that plotting helps to avoid collisions and that, if the officer on watch is to meet this need, he should call for assistance on the bridge whenever the screen shows the smallest echo.

A completely fresh approach should therefore be made to the problem of recording (at present confined to the reflection-plotter) aimed at making it accurate and automatic. In the first place, by pressing a button, the officer on watch should be able to bring into action an automatic record, at regular intervals, of time, heading and speed. Secondly, by operating a key he should be able to add to these factors bearing and range of an echo. Finally, should there be several echoes, he must be able, the moment he observes any one of them, to start an automatic recording of each of these five factors.

In most railway stations you will find weighing machines available to the public. You stand on a platform, insert a coin, and the machine immediately delivers a ticket on which your weight is indicated by an arrow. This is the sort of record I have in mind for each of the five factors. As a first suggestion, I should be in favour of recording the time in tenths of a minute, and angles in degrees, with an easy means of interpolation to a greater accuracy. For distance, accuracy would vary with the scale.

It has often been said, and Captain Wepster says it once more, that plotting is impossible when there are a number of echoes. Even if you have as many as fifty, however, only four or five at the most represent a collision risk, and a memorytube shows them at a glance by depicting their track. The device suggested above would make it possible to record in thirty seconds the data relating to five echoes. As, following Captain Wylie, I explained in my little book on radar, such recording is in itself an effective form of plotting, far superior to the reflection-plotter.

I fully admit, of course, the usefulness of the latter, but in multiple encounters it is soon overloaded, and can in no way provide anything like the accuracy of an efficient recording. On the other hand, such recording would in itself serve to cut down the work on the plotter to a simplified marking of the time and position of the different echoes, and to eliminate, as observation proceeded, all that were then seen to be irrelevant. Thus the plots drawn on the plotter, which would no longer have to be numbered, and would show only what was needed, would be easier to interpret. The combination of reflection-plotter and recording would obviate the need for geometric plotting, a process generally unpractical because of its length. Unlike many innovations that attract much attention even though they are technically unpractical or economically prohibitive, automatic recording should be accepted as a vital necessity. So long as we are without it, half the information supplied by radar will continue to be wasted. 
Radar came out of the war with a glory that gave a false impression of the ease with which it could be adapted to peaceful purposes. This adaptation involved considerable research by manufacturers into the techniques of radar, and by users into ways of using it at sea. It was the users who first achieved success by having a code of radar conduct agreed. This done they can maintain that the manufacturers have not yet given them the means to put the code into proper operation.

Having already seen in the realm of radar use and traffic regulation at sea, how true it is that unity is strength, mariners are now in a position to say to the manufacturers: 'You have already offered us all sorts of good things, but to satisfy us completely you should give us compass-rose presentation and automatic recording'.

\section{REFERENCES}

1 Sadler, D. H. (1957). The mathematics of collision avoidance at sea, this Journal, 10, 306 .

2 The value of a mathematical approach to the collision problem, this Journal, 16, $189(1963)$.

3 Wepster, A. (1962). The arrangement of navigational equipment in modern cargo vessels, this Journal, 15, 241.

\section{The Sun-Star Chronometer}

from Air Marshal Sir Edward Chilton, K.B.E., C.B.

THE Sun-Star Chronometer described in this note has been developed by Raymond Nardin of Switzerland and Oscar E. Batori of the United States; it is manufactured by Ulysse Nardin and produced by the Batori Computer Company Inc. of New York. It contains interesting features which merit description.

The Chronometer has two movements of different speeds, one corresponding to solar time and the other to sidereal time, connected by a planetary differential mechanism and regulated by a single system, so that the two movements have a common rate and can be stopped and started simultaneously. All the hands (including the second hands) can be set and a single correction can be applied for either solar or sidereal time.

The Chronometer, which indicates simultaneously, solar and sidereal time, is designed primarily for navigation by the stars: G.H.A. Aries is available on inspection, as Mean Time is from an ordinary watch. In the illustration the time is shown as G.M.T. $15^{\mathrm{h}} 2 \mathrm{I}^{\mathrm{m}} 28^{\mathrm{s}}$ and G.H.A. Aries (or Sun) $49^{\circ} 03^{\prime} 50^{\prime \prime}$. The hands for time and arc are differentiated by colour.

G.H.A. Sun can be obtained by making a correction of $2: 5$ per hour over short periods, or 59:1 per day and an average equation of time for longer periods. These corrections can be precalculated. 